\title{
Transplante de glândulas salivares menores no tratamento da ceratoconjuntivite seca em cães
}

[Transplantation of the minor salivary gland in dogs with keratoconjunctivitis sicca]

\author{
G.T. Angélico ${ }^{1}$, J.J.T. Ranzani ${ }^{2}$, C.V.S. Brandão ${ }^{2}$, S.A. Schellini ${ }^{3}$, C.R. Padovani ${ }^{2}$, \\ M.G. Sereno ${ }^{1}$, D.N. Cremonini ${ }^{1}$
}

\author{
${ }^{1}$ Aluna de pós-graduação - Faculdade de Medicina Veterinária e Zootecnia-UNESP - Botucatu, SP \\ ${ }^{2}$ Faculdade de Medicina Veterinária e Zootecnia-UNESP - Botucatu, SP \\ ${ }^{3}$ Faculdade de Medicina de Botucatu - FMB - UNESP - Botucatu, SP
}

\begin{abstract}
RESUMO
Relatou-se o efeito do transplante de glândulas salivares menores (TGSM) em cães portadores de ceratoconjuntivite seca (CCS) e estudaram-se os efeitos da secreção dessas glândulas usadas como alternativa de lubrificação ocular. A aplicação da técnica foi satisfatória, uma vez que resultou em melhora no quadro clínico oftalmológico sem que houvesse mínimas intercorrências pós-operatórias.
\end{abstract}

Palavras-chave: cão, ceratoconjuntivite seca, transplante, glândulas salivares menores

\begin{abstract}
The effect of the transplant of minor salivary gland (TGSM) in carrying dogs of dry ceratoconjuntivite (CCS) and the effect of these used glands as alternative for ocular lubrication have been studied. The transplantation of the salivary gland in dogs with keratoconjunctivitis sicca (KCS) was reported and clinical effects of the salivary secretion as ocular lubricant for the relief of the disease were studied. Based on these results, it was concluded that the application of the TMSG technique in dogs with KCS is satisfactory, as demonstrated by improvement in the clinical ophthalmology and appreciated by the landlord regardin the results of the surgery and minimal postoperative complications.
\end{abstract}

Keywords: dog, keratoconjunctivitis sicca, transplantation, minor salivary gland

\section{INTRODUÇÃo}

A ceratoconjuntivite seca (CCS) é uma doença ocular inflamatória crônica comum no cão, a qual resulta em ressecamento da conjuntiva e da córnea (Giuliano e Moore, 2007; Herrera, 2008; Galera et al., 2009). As alterações que induzem a CCS são, basicamente, a ausência de atividade lacrimal e a ausência da glândula ou atrofia glandular. Clinicamente a CCS manifesta-se com secreção ocular mucoide, blefaroespasmo, hiperemia conjuntival, vascularização corneana, fibrose, pigmentação corneana, dor ocular, doença corneana progressiva e déficit de acuidade visual (Berdoulay et al., 2005; Duarte et al., 2007; Herrera, 2008). O diagnóstico é baseado nos sinais clínicos e nos resultados obtidos dos exames específicos, tais como: tempo de quebra do filme lacrimal, corantes da superfície ocular (fluoresceína, rosa bengala, lissamina verde) e teste lacrimal de Schirmer (Laus e Oriá, 1999; Herrera, 2008; Galera et al., 2009).

O tratamento clínico utilizando colírios proporciona boa melhora em $90 \%$ dos casos de CCS (Galera et al., 2009), entretanto há necessidade da dedicação e disponibilidade dos proprietários dos animais. Alguns procedimentos cirúrgicos podem ser indicados quando 0 tratamento clínico é ineficaz, tais como: tarsorrafia parcial, oclusão do ponto lacrimal, transposição do ducto parotídeo e transplante das glândulas salivares (TGS) (Murube, 1986;

Recebido em 6 de julho de 2010

Aceito em 13 de julho de 2011

E-mail: geovanathais@yahoo.com.br 
Murube, 1998; Soares e França, 2005; Giuliano e Moore, 2007). As glândulas salivares menores possuem uma secreção seromucosa que, juntamente com um componente aquoso, torna seu produto biofísica e bioquimicamente muito semelhante à lágrima, assim, é bem tolerada pela superfície ocular (Gomes e Alves, 2006). O TGS menores (GRSM) visa substituir a lágrima pela secreção salivar por meio de transplantes de glândulas salivares para o fórnice conjuntival (Murube, 1986; Murube, 1998; Gomes e Alves, 2006).

Apesar de utilizada na medicina, na literatura veterinária consultada não há relatos da aplicação da técnica de TGSM em cães. Frente aos aspectos descritos e ressaltando a necessidade da utilização de novos tratamentos para a CCS, o presente estudo teve por objetivos relatar o efeito do TGSM em cães portadores de CCS, estudar clinicamente os efeitos da secreção dessas glândulas como alternativa de lubrificação ocular e avaliar se o TGSM pode ser um meio terapêutico efetivo para o tratamento da CCS em cães.

\section{MATERIAL E MÉTODOS}

Os procedimentos experimentais desenvolvidos foram aprovados pela Câmara de Ética em Experimentação Animal da Faculdade de Medicina Veterinária e Zootecnia da Universidade Estadual Paulista, Botucatu, SP, protocolo $n^{0} 130 / 2007$. A cirurgia foi realizada em 16 olhos de cães da raça Cocker Spaniel, portadores de CCS, diagnosticados no serviço de oftalmologia veterinária do Hospital Veterinário Escola. Para tal, foram selecionados somente cães com olhos com intenso sofrimento da superfície ocular e, principalmente, casos não responsivos à terapia clínica.

Os animais foram submetidos ao exame clínico oftalmológico com iluminação direta, teste lacrimal de Schirmer I (TLS; Ophthalmos ${ }^{\circledR}$, Brasil), corante de rosa bengala (Ophthalmos ${ }^{\circledR}$, Brasil), corante de fluoresceína (Ophthalmos®, Brasil) e tonometria (Tonômetro de aplanação Tono Pen ${ }^{\circledR}$; Medtronic). Todos os pacientes apresentavam valores de TLS menor que $9 \mathrm{~mm} / \mathrm{min}$, com características clínicas de CCS, e estavam sendo tratados clinicamente, sem sucesso. O conjunto glândulo-mucoso foi obtido do próprio animal, a partir da mucosa oral localizada na região mandibular, próximo à comissura bucal (Fig. 1A). Procedeu-se à incisão em elipse da mucosa oral, com $0,5 \mathrm{~cm}$ de comprimento por $0,5 \mathrm{~cm}$ de largura, aprofundando-se até o plano muscular. Em seguida, com uma tesoura de pontas rombas, excisou-se o enxerto pela dissecção entre o manto glandular e o plano muscular (Fig. 1B).

O enxerto foi retirado em um conjunto único, constituído pela mucosa e glândula salivar subjacente. A área doadora foi fechada com uma sutura contínua de fio absorvível poliglactina 60 . O transplante de glândula foi realizado bilateralmente em todos os cães e a área receptora foi o fórnice superior. Inicialmente a pálpebra foi evertida e, em seguida, injetou-se anestésico de lidocaína $2 \%$ sem vasoconstritor no espaço subconjuntival para separar a mucosa do plano muscular subjacente e facilitar a dissecção. A conjuntiva foi incisada paralela à rima palpebral na porção mediana da pálpebra superior, com distância de $0,5 \mathrm{~cm}$ a partir do canto medial.

Na maioria dos casos, a simples incisão da mucosa provocou sua retração, deixando o leito aberto em forma de elipse, necessitando apenas da dissecção das margens da ferida, as quais foram depois suturadas ao enxerto. O objetivo foi criar uma área cruenta fusiforme na face conjuntival da pálpebra superior, de aproximadamente $0,5 \mathrm{~cm}$ de comprimento por $0,5 \mathrm{~cm}$ de profundidade. O material glândulomucoso foi, então, posicionado no leito receptor com a face glandular em contato com a superfície cruenta. A conjuntiva foi suturada à mucosa do enxerto, com pontos simples separados invertidos, com fio absorvível de poliglactina 6-0 (Vicryl ${ }^{\circledR}$; Ethicon-Johnson \& Johnson Ltda., Brasil; Fig. 2A).

A medicação pós-operatória incluiu colírio antimicrobiano - ciprofloxacina 0,03 (Ciloxan ${ }^{\circledR}$; Alcon Laboratórios do Brasil Ltda.), uma gota a cada seis horas, durante 15 dias -, colírio antiinflamatório não esteroidal - diclofenaco (Still ®; Allergan Laboratórios do Brasil Ltda.), uma gota a cada oito horas, durante 15 dias -, antimicrobiano sistêmico - enrofloxacina (Flotril (R; Schering Plough, Brasil), 5mg/kg, a cada 12 horas durante 10 dias - e anti-inflamatório não esteroidal sistêmico - meloxicam (Maxicam ${ }^{\circledR}$; Ourofino Pet, Brasil), 0,1mg/kg a cada 24 horas, durante quatro dias. 

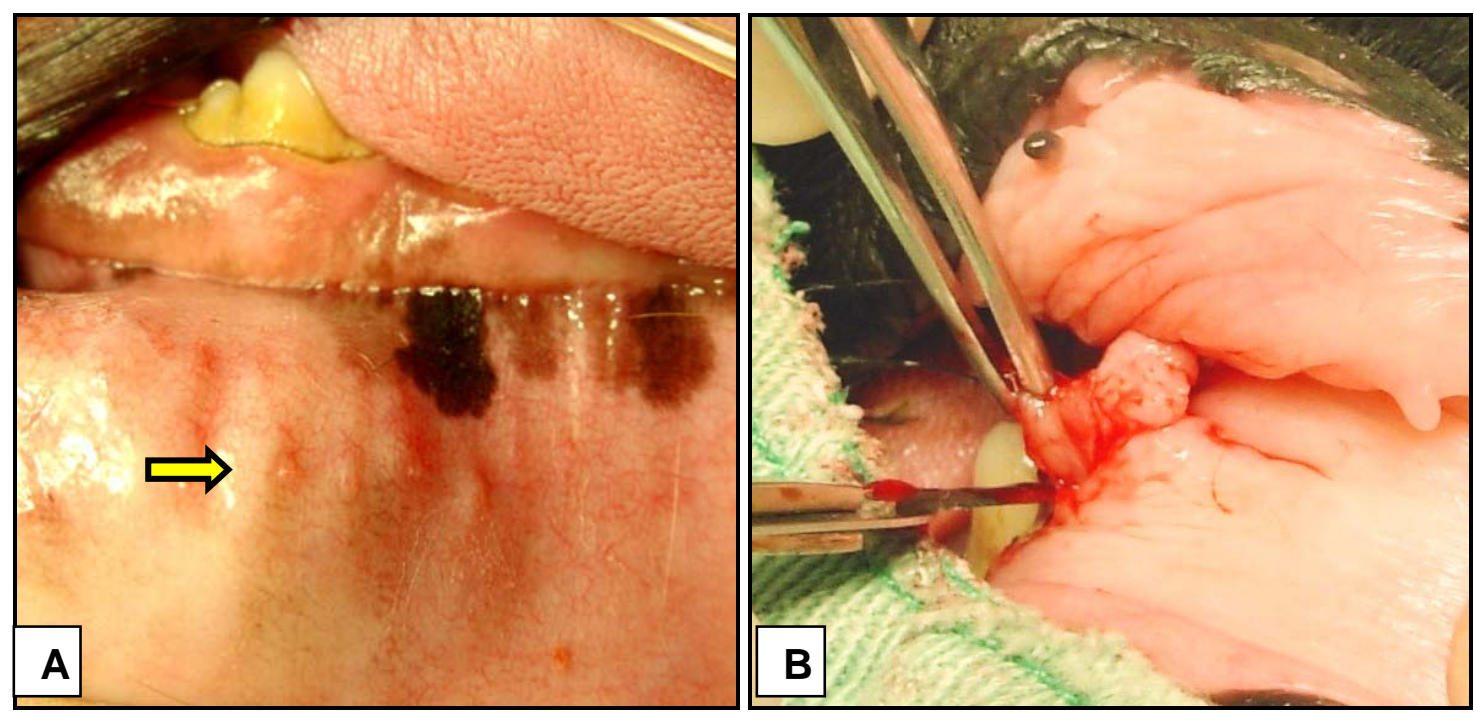

Figura 1. Cão. (A): mucosa conjuntival oral na região mandibular, próximo à comissura bucal; observar as saliências das glândulas salivares menores (setas); (B): coleta do enxerto na mucosa conjuntival oral, próximo à comissura bucal.

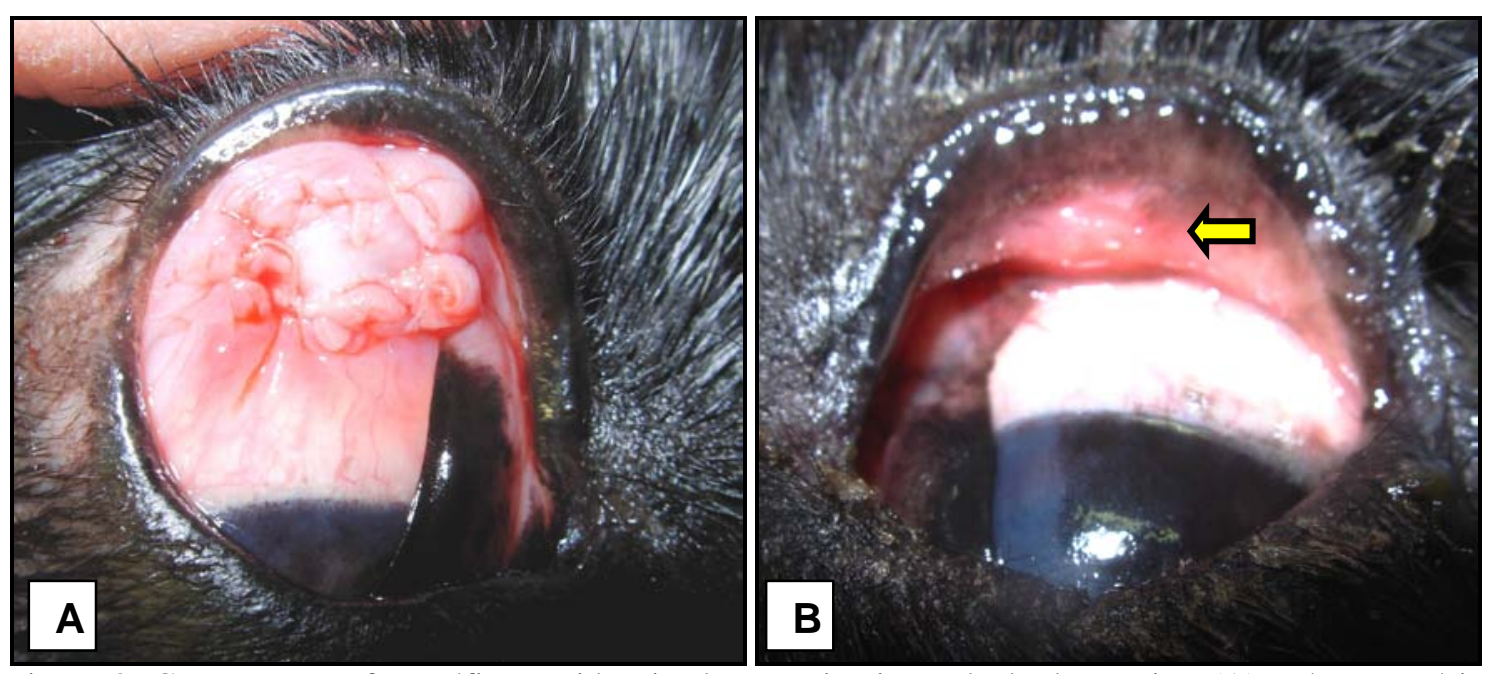

Figura 2. Cão. Imagens fotográficas evidenciando a conjuntiva palpebral superior. (A): pós-operatório imediato; (B): aspecto do local do transplante após 60 dias da cirurgia (seta).

Os animais foram acompanhados semanalmente, por meio de anamnese e exame clínico oftalmológico, desde o momento da cirurgia até o último retorno, aos 60 dias pós-cirúrgicos. Para os dados da anamese foi aplicado, em todos os momentos de avaliação, um questionário, no qual os proprietários quantificavam a presença da secreção ocular e a frequência com que realizavam a higienização ocular; este dado foi denominado de grau de insatisfação do proprietário, o qual foi classificado em escores de 0 a 4, sendo 0 : ausência, 1: leve, 2: moderado,
3: elevado, 4: intenso. O exame clínicooftalmológico foi feito sempre pelo mesmo examinador. Para tanto, foram avaliadas as seguintes variáveis: deiscência de pontos da glândula transplantada, necrose e cicatrização do enxerto glandular e secreção ocular, seguindo o sistema acima descrito. A classificação referente à coloração de rosa bengala, seguindo os padrões de Van Bijsterveld (1969), foi realizada por um examinador que desconhecia os momentos de avaliação dos cães. 


\section{RESULTADOS}

Com os resultados obtidos pela anamnese, verifica-se que houve significativa redução da quantidade de secreção e do número de higienizações oculares necessárias do dia zero para o dia 60 pós-cirúrgico. Na avaliação clínica oftalmológica pós-operatória, observou-se que houve discreto a moderado edema e congestão das pálpebras e da conjuntiva, que desapareceram após oito a 10 dias. Verificou-se que os enxertos apresentaram-se com aspecto pálido nas primeiras 24 horas, readquirindo sua coloração rosada original a partir do segundo dia do pós-operatório, que foi mantida até o final da observação (Fig. 2B).

O alívio dos sintomas da CCS foi observado logo na segunda semana do pós-operatório, traduzido pela recuperação do brilho da superfície ocular acompanhado de grande diminuição do quadro irritativo, da fotofobia e do blefaroespasmo presentes no M0. Em relação à secreção ocular, 15 olhos (93,7\%) apresentaram melhora, e um olho $(6,3 \%)$ a manteve constante. Não houve nenhum caso de necrose do enxerto e somente um caso de deiscência de pontos, o qual ocorreu devido a não utilização do colar de restrição, de uso obrigatório e de responsabilidade do proprietário, durante o período de pós-operatório.

As complicações observadas foram a presença de ceratite ulcerativa em três olhos na avaliação de sete dias, o que ocorreu provavelmente em razão do contato do fio com a superfície córnea e foi resolvido no período médio de sete dias. Na área doadora no lábio, verificou-se aparência semelhante à de um leve trauma cirúrgico no período inicial da avaliação, sem dor ou incômodos, com rápida cicatrização.

Em relação ao TLS, nove olhos (56,3\%) mostraram aumento na produção lacrimal, três $(18,7 \%)$ permaneceram constantes e quatro (25\%) apresentaram valores mais baixos que no dia zero (Tab. 1). Quanto à coloração de rosa bengala, em seis olhos $(37,5 \%)$ ocorreu diminuição da impregnação do corante, em cinco (31,2\%) permaneceu semelhante e em cinco (31,2\%) houve aumento.

Para comparações utilizou-se teste não paramétrico para o modelo de medidas repetidas em grupos independentes (Zar, 1999).

Tabela 1. Resultados do teste lacrimal de Schirmer ( $\mathrm{mm} / \mathrm{min})$, em cães portadores de ceratoconjuntivite seca submetidos ao transplante de glândulas salivares menores

\begin{tabular}{ccccccccccccccccc} 
& T1 & T2 & T3 & T4 & T5 & T6 & T7 & T8 & T9 & T10 & T11 & T12 & T13 & T14 & T15 & T16 \\
\hline M0 & 5 & 7 & 7 & 3 & 5 & 0 & 0 & 5 & 0 & 0 & 0 & 0 & 4 & 9 & 4 & 8 \\
M60 & 6 & 5 & 14 & 10 & 4 & 3 & 0 & 14 & 0 & 3 & 3 & 3 & 2 & 5 & 4 & 14 \\
\hline
\end{tabular}

T1 a T16: cães avaliados; M0: momento da primeira consulta; M60: consulta no dia 60 do pós-operatório.

\section{DISCUSSÃO}

A CCS é uma doença ocular inflamatória crônica comum no cão, que pode resultar em perda da acuidade visual (Giuliano e Moore, 2007; Herrera, 2008). Entende-se, portanto, a importância de novos tratamentos, principalmente para impedir a progressão da doença em cães não responsivos aos tratamentos convencionais. Apesar das inúmeras fórmulas de produtos estimulantes e/ou substitutivos da lágrima, o tratamento conservador nos casos graves é, ainda, frustrante e não suficientemente eficaz, necessitando de disciplina rigorosa dos proprietários por toda a vida do animal. Alguns procedimentos cirúrgicos podem ser indicados com o objetivo de melhorar a qualidade de vida dos pacientes (Soares e França, 2005), motivo pelo qual se justifica o empenho em desenvolver novas alternativas de tratamento para a CCS. Ainda sem relatos na literatura médica veterinária consultada, este trabalho teve o objetivo de adaptar a técnica cirúrgica humana de TGSM, desenvolvida por Murube (1998) e modificada por Soares e França (2005), em cães portadores de CCS, não responsivos à terapia clínica.

De acordo com Guerrissi e Belmonte (2004), em humanos o enxerto deve ser obtido da mucosa do lábio superior pela grande concentração de glândulas salivares menores e pelo fácil acesso cirúrgico em comparação com outras regiões. Com o objetivo de padronizar o local da coleta das glândulas salivares menores em cães, no presente estudo, após o mapeamento histológico, constatou-se maior número glandular na região do lábio lateral inferior próximo à comissura 
bucal, indicando-a como o local ideal para a coleta, além de ser o de melhor acesso.

A técnica descrita por Soares e França (2005) indicou que a área doadora é suturada de forma contínua com náilon 6-0. Neste estudo, a fim de evitar uma provável necessidade de sedação dos cães para a retirada dos pontos, optou-se pela realização de uma sutura contínua com fio absorvível de poliglactina 6-0, o que resultou em grande vantagem no manejo pós-operatório e com aparência final semelhante aos 60 dias, além de discreta cicatriz após leve trauma cirúrgico, sem dor ou incômodos e com rápida cicatrização.

Diferentemente do proposto por Soares e França (2005), a área de eleição para se fixar o enxerto foi a pálpebra superior, pois a presença da terceira pálpebra nos cães, localizada na pálpebra inferior, poderia ocasionar microtraumas por contato com o enxerto e interferir nos resultados pós-operatórios. Com o propósito de evitar o risco da perda do enxerto e minimizar a provável ocorrência de lesões corneanas, a sutura da conjuntiva palpebral com a mucosa do enxerto foi realizada com fio absorvível de poliglactina 6-0, na forma de pontos simples separados invertidos, diferindo, assim, da técnica de Soares e França (2005), que utilizaram o fio de náilon 60 em padrão contínuo.

Confirmando resultados já relatados por Murube (1997) e Gomes e Alves (2006), a utilização de glândulas salivares menores proporcionou significativa melhora do quadro clínico oftalmológico, notada no período pós-operatório imediato, e assim permaneceu, na maioria dos casos. Semelhante aos resultados relatados por Soares e França (2005), neste experimento a melhora da lubrificação foi comprovada pelos resultados obtidos nos dias zero e 60 póscirurgicos, mostrando a recuperação do brilho ocular, aumento dos valores do TSL em 56\% e diminuição da secreção ocular. Isso justifica a desvinculação de terapias clínicas em mais de $50 \%$ dos olhos operados, também demonstrado pelos autores, nos quais a produção lacrimal do enxerto foi suficiente e estável.

A formação de depósito de precipitados cristaloides na córnea e na margem palpebral, que ocorre após a cirurgia de transposição do ducto parotídeo, descrita por Taffarel et al. (2002), não foi observada nos animais do presente estudo após o TGSM. Essas glândulas, além de secretar saliva, mostram que sua composição é principalmente rica em mucoproteínas com alta concentração de IgA secretora (Liquidato e Bussoloti Filho, 2005). Murube (1997) descreveu que, na medicina, os pacientes submetidos à transposição do ducto parotídeo apresentavam epífora durante as refeições, em razão do estímulo da glândula parótida. Na medicina veterinária, Birchard et al. (1996) descreveram que alguns proprietários de cães submetidos à transposição do ducto parotídeo reclamaram de severa epífora, suficiente para indicar a recolocação do ducto parotídeo em seu local original. Semelhante ao relatado por Soares e França (2005), a epífora prandial não ocorreu nos pacientes do atual estudo e a satisfação do proprietário em relação ao TGSM foi relatada na maioria dos animais.

\section{CONCLUSÕES}

A aplicação da técnica de TGSM em cães portadores de CCS é viável, simples, de fácil execução e consiste em boa opção no tratamento dessa doença. A avaliação dos animais em longo prazo deve ser estimulada.

\section{REFERÊNCIAS BIBLIOGRÁFICAS}

BERDOULAY, A.; ENGLISN, R.V.; NADELSTEIN, B. Efeito tópico da suspensão aquosa de tacrolimus $0,02 \%$ na produção lacrimal em cães com ceratoconjuntivite seca. Vet. Ophthalmol., v.8, p.225-232, 2005.

BIRCHARD, S.J.; BOJRAB, M.J.; TOMLISON, J.L. Técnicas atuais em cirurgia de pequenos animais. 3.ed. São Paulo: Roca, 1996. 896p.

DUARTE, M.C.B.; PINTO, T.N.; MOREIRA, H. et al. Nível de testosterona total em mulheres pós-menopausa com olho seco. Arq. Bras. Oftalmol., v.70, p.465-469, 2007.

GALERA, P.D.; LAUS, J.L.; ORIÁ, A.P. Afecções da túnica fibrosa. In: LAUS, J.L. Oftalmologia clínica e cirúrgica em cães e gatos. São Paulo: Roca, 2009. p.69-96.

GIULIANO, E.A.; MOORE, C.P. Diseases and surgery of the lacrimal secretory system. In: GELATT, K.N. Veterinary ophthalmology. 4.ed. Florida: Black Well, 2007. p.633-661. 
GOMES, J.A.P.; ALVES, M.R. Superfície ocular. São Paulo: Cultura Médica, 2006. 391p.

GUERRISSI, J.O.; BELMONTE, J. Surgical treatment of dry eye sindrome: Conjunctival graft of the minor salivary gland. J. Craniofacial Surg., v.1, p.6-9, 2004.

HERRERA, D. Afecções da córnea, In: HERRERA, D. Oftalmologia clínica em animais de companhia. São Paulo: MedVet, 2008. p.111140.

LAUS, J.L.; ORIÁ, A.P. Doenças corneanas em pequenos animais. Rev. Educ. Contin. CRMV-SP, v.2, p.26-33, 1999.

LIQUIDATO, B.M.; BUSSOLOTI FILHO, I. Lip's lesser salivary gland biopsy. Tec. Otorrinolaringol., v.23, p.20-22, 2005.

MURUBE, D.C. Transplation of salivary gland to the lacrimal basin. Scand. J. Reumathol., v.61, p.264-267, 1986.
MURUBE, J. Cirúgia substitutiva del ojo seco y transplantes glandulares. In: MURUBE, J. Ojo seco. Quito: Tecnimedia, 1997. cap.4, p.207-221.

MURUBE, J. Labial salivary gland transplation in severe dry eye. Oculoplast. Rec. Surg., v.1, p.104-110, 1998.

SOARES, E.J.C.; FRANÇA, F.P. Transplante de glândulas salivares labiais no tratamento do olho seco grave. Arq. Bras. Oftalmol., v.68, p.481489, 2005.

TAFFAREL, M.O.; CAVALCANTE, C.Z.; CUNHA, O. Ceratoconjuntivite seca. Rev. Nosso Clin., v.5, p. 6-12, 2002.

VAN BIJSTERVELD, O.P. Diagnostic tests in the sicca syndrome. Arch. Ophthalmol., v.1, p.10-14, 1969.

ZAR. J.H. Biostatitical analysis. 4 ed. New Jersey: Prentice Hall, 1999. 663p. 